\title{
Low 2016/17 season vaccine effectiveness against hospitalised influenza A(H3N2) among elderly: awareness warranted for $2017 / 18$ season
}

Marc Rondy ${ }^{1}$, Alin Gherasim ${ }^{2,3}$, Itziar Casado ${ }^{3,4}$, Odile Launay ${ }^{5,6}$, Caterina Rizzo7, Daniela Pitigoi, Aukse Mickiene ${ }^{9}$, Sierk D Marbus $^{10}$, Ausenda Machado ${ }^{11}$, Ritva K Syrjänen ${ }^{12}$, Iva Pem-Novose ${ }^{13}$, Judith Krisztina Horváth ${ }^{14}$, Amparo Larrauri'2,3, Jesús Castilla $a^{3,4}$, Philippe Vanhems ${ }^{5,15,16}$, Valeria Alfonsi ${ }^{7}$, Alina E Ivanciuc ${ }^{17}$, Monika Kuliese ${ }^{9}$, Rianne van Gageldonk-Lafeber ${ }^{10}$, Veronica Gomez $^{11}$, Niina Ikonen ${ }^{18}$, Zvjezdana Lovric ${ }^{13}$, Annamária Ferenczi ${ }^{14}$, I-MOVE+ hospital working group ${ }^{19}$, Alain Moren ${ }^{1}$

1. EpiConcept, Paris, France

2. National Centre of Epidemiology, Institute of Health Carlos III, Madrid, Spain

3. CIBER Epidemiología y Salud Pública, Institute of Health Carlos III, Madrid, Spain

4. Instituto de Salud Pública de Navarra, IdiSNA, Pamplona, Spain

5. Inserm, F-CRIN, Innovative clinical research network in vaccinology (I-REIVAC), CIC 1417, Paris, France

6. Université Paris Descartes, Sorbonne Paris Cité, APHP, CIC Cochin-Pasteur, Paris, France

7. Istituto Superiore di Sanità, Rome, Italy

8. University of Medicine and Pharmacy Carol Davila, National Institute for Research Cantacuzino, Bucharest, Romania

9. Department of Infectious diseases of Lithuanian University of Health Sciences, Kaunas, Lithuania

10. Centre for Epidemiology and surveillance of infectious diseases, Centre for Infectious disease control, National Institute for Public Health and the Environment (RIVM), Bilthoven, The Netherlands

11. Epidemiology Research Unit, Epidemiology Department, National Health Institute Doutor Ricardo Jorge, Lisbon, Portugal

12. Impact Assessment Unit, National Institute for Health and Welfare, Tampere, Finland

13. Epidemiology Service, Croatian Institute of Public Health, Zagreb, Croatia

14. Office of the Chief Medical Officer, Budapest, Hungary

15. Infection Control and Epidemiology Unit, Hôpital Edouard Herriot, Hospices Civils de Lyon, Lyon, France

16. Emerging Pathogens Laboratory - Fondation Mérieux, Centre International de Recherche en Infectiologie, INSERM U1111, Centre National de la Recherche Scientifique (CNRS), UMR5308, Ecole Nationale Supérieure (ENS) de Lyon, Université Claude Bernard Lyon 1, Lyon, France;

17. National Institute for Research Cantacuzino, Bucharest, Romania, Faculty of Biology, Bucharest University

18. Unit of Expert Microbiology, National Institute for Health and Welfare, Helsinki, Finland

19. The members of the I-Move+ hospital working group are listed at the end of the article

Correspondence: Marc Rondy (m.rondy@epiconcept.fr)

Citation style for this article: Rondy Marc, Gherasim Alin, Casado Itziar, Launay Odile, Rizzo Caterina, Pitigoi Daniela, Mickiene Aukse, Marbus Sierk D, Machado Ausenda, Syrjänen Ritva K,
Pem-Novose Iva, Horváth Judith Krisztina, Larrauri Amparo, Castilla Jesús, Vanhems Philippe, Alfonsi Valeria, Ivanciuc Alina E, Kuliese Monika, van GageldonkLafeber Rianne, Gomez Veronica, Ikonen Niina, Lovric Zvjezdana, Ferenczi Annamária, I-MOVE+ hospital working group, Moren Alain. Low 2016/17 season vaccine effectiveness against hospitalised influenza $\mathrm{A}\left(\mathrm{H}_{3} \mathrm{~N}_{2}\right)$ among elderly: awareness warranted for 2017/18 season. Euro Surveill. 2017;22(41):pii=17-00645. https:// doi.org/10.2807/1560-7917.ES.2017.22.41.17-00645

In a multicentre European hospital study we measured influenza vaccine effectiveness (IVE) against $\mathrm{A}\left(\mathrm{H}_{3} \mathrm{~N}_{2}\right)$ in $2016 / 17$. Adjusted IVE was $17 \%$ (95\% confidence interval (Cl): 1 to 31$)$ overall; $25 \%$ ( $95 \% \mathrm{Cl}: 2$ to 43 ) among 65-79-year-olds and $13 \%(95 \% \mathrm{Cl}:-15$ to 30$)$ among those $\geq 80$ years. As the $A\left(\mathrm{H}_{3} \mathrm{~N}_{2}\right)$ vaccine component has not changed for $2017 / 18$, physicians and public health experts should be aware that IVE could be low where $\mathrm{A}\left(\mathrm{H}_{3} \mathrm{~N}_{2}\right)$ viruses predominate.

In $2016 / 17$, the influenza season in Europe was characterised by an early start (week 46, 2016) and a predominance of $\mathrm{A}\left(\mathrm{H}_{3} \mathrm{~N}_{2}\right)$ viruses. Overall, $89 \%$ of strains reported to the European Centre for Disease Prevention and Control $(E C D C)$ were $A\left(\mathrm{H}_{3} \mathrm{~N}_{2}\right)$ viruses [1]. High hospitalisation rates and case fatality ratios were reported among persons aged 65 years and above [2]. The I-MOVE + (Integrated Monitoring of Vaccines in Europe plus) hospital network early estimates, suggested a low 2016/17 seasonal influenza vaccine effectiveness (IVE) against hospitalisation with influenza $A\left(\mathrm{H}_{3} \mathrm{~N}_{2}\right)$ among persons aged 65 years and above in the European Union (EU) [3].

Since the $A\left(\mathrm{H}_{3} \mathrm{~N}_{2}\right)$ vaccine component has not changed in $2017 / 18$, we present the final $2016 / 17$ season IVE against hospitalisation with influenza $A\left(\mathrm{H}_{3} \mathrm{~N}_{2}\right)$ among persons aged 65 years and above in Europe, to inform on the level of IVE that can be expected against $A\left(H_{3} N_{2}\right)$ in the upcoming $2017 / 18$ season.

\section{Study design}

We conducted a multicentre hospital-based test-negative design (TND) case-control study in 27 hospitals from 10 countries (Croatia, Finland, France, Hungary, Italy, Lithuania, the Netherlands, Portugal, Romania and Spain) according to a generic protocol adapted to each local setting [4]. The detailed methods are described elsewhere [5]. In brief, hospital teams identified and swabbed patients aged 65 years and above, 
TABLE 1

Characteristics of influenza $\mathrm{A}(\mathrm{H} 3 \mathrm{~N} 2)$ hospitalised cases $(\mathrm{n}=1,073)$ and test-negative controls $(\mathrm{n}=1,541), \mathrm{I}-\mathrm{MOVE}+$ study, Europe, influenza season 2016/17

\begin{tabular}{|c|c|c|c|c|}
\hline & \multicolumn{2}{|c|}{$\begin{array}{c}\text { Influenza } A\left(\mathrm{H}_{3} \mathrm{~N}_{2}\right) \text { cases } \\
(\mathrm{n}=1,073)\end{array}$} & \multicolumn{2}{|c|}{ Controls $(n=1,541)$} \\
\hline Median age in years (range) & \multicolumn{2}{|c|}{$81(65-102)$} & \multicolumn{2}{|c|}{$80(65-102)$} \\
\hline Characteristic & $\mathrm{n} / \mathrm{N}^{\mathrm{a}}$ & $\%$ & $\mathrm{n} / \mathrm{N}^{\mathrm{a}}$ & $\%$ \\
\hline Aged $65-69$ years & $457 / 1,073$ & 42.6 & $770 / 1,541$ & 50.0 \\
\hline Sex $=$ male & $516 / 1,072$ & 48.1 & $815 / 1,535$ & 53.1 \\
\hline $2016 / 17$ seasonal influenza vaccination & $556 / 1,073$ & 51.8 & $894 / 1,541$ & 58.0 \\
\hline $2015 / 16$ seasonal influenza vaccination & $578 / 1,054$ & 54.8 & $896 / 1,525$ & 58.8 \\
\hline \multicolumn{5}{|l|}{ Current and previous vaccination status } \\
\hline $2016 / 17$ seasonal vaccine only & $46 / 1,054$ & 4.4 & $99 / 1,525$ & 6.5 \\
\hline $2015 / 16$ seasonal vaccine only & $73 / 1,054$ & 6.9 & $112 / 1,525$ & 7.3 \\
\hline $2015 / 16$ and $2016 / 17$ seasonal vaccines & $505 / 1,054$ & 47.9 & $784 / 1,525$ & 51.4 \\
\hline \multicolumn{5}{|l|}{ Type of $2016 / 17$ vaccine } \\
\hline Not vaccinated & $517 / 1,007$ & 48.2 & $647 / 1,421$ & 42.0 \\
\hline Inactivated subunit egg & $243 / 1,007$ & 22.6 & $431 / 1,421$ & 28.0 \\
\hline Inactivated split virion egg & $229 / 1,007$ & 21.3 & $321 / 1,421$ & 20.8 \\
\hline Adjuvanted & $18 / 1,007$ & 1.7 & $22 / 1,421$ & 1.4 \\
\hline \multicolumn{5}{|l|}{ Underlying conditions } \\
\hline Diabetes mellitus & $325 / 1,072$ & 30.3 & $473 / 1,540$ & 30.7 \\
\hline Heart disease & $710 / 1,070$ & 66.4 & $1,032 / 1,541$ & 67.0 \\
\hline Lung disease & $392 / 1,069$ & 36.7 & $672 / 1,534$ & 43.8 \\
\hline Cancer & $201 / 1,069$ & 18.8 & $369 / 1,533$ & 24.1 \\
\hline Renal disease & $223 / 1,071$ & 20.8 & $319 / 1,539$ & 20.7 \\
\hline Stroke & $125 / 879$ & 14.2 & $176 / 1,287$ & 13.7 \\
\hline Rheumatologic disease & $157 / 1,070$ & 14.7 & $341 / 1,539$ & 22.2 \\
\hline Obesity $^{b}$ & $124 / 1,062$ & 11.7 & $154 / 1,527$ & 10.1 \\
\hline Any underlying condition & $996 / 1,063$ & 93.7 & $1,456 / 1,531$ & 95.1 \\
\hline At least two underlying conditions & $776 / 1,025$ & 75.7 & $1,206 / 1,491$ & 80.9 \\
\hline Functional impairment & $399 / 1,066$ & 37.4 & $588 / 1,529$ & 38.5 \\
\hline Hospitalisations in past 12 months & $353 / 1,063$ & 33.2 & $668 / 1,526$ & 43.8 \\
\hline Current smoker & $182 / 901$ & 20.2 & $318 / 1,220$ & 26.1 \\
\hline \multicolumn{5}{|l|}{ Potential for misclassification } \\
\hline Antivirals received before swabbing & $177 / 1,069$ & 16.0 & $90 / 1,535$ & 5.8 \\
\hline Swabbing within 3 days of symptom onset & $653 / 1,073$ & 58.7 & $876 / 1,541$ & 56.2 \\
\hline \multicolumn{5}{|l|}{ Study sites } \\
\hline Croatia & $31 / 1,073$ & 2.9 & $13 / 1,541$ & 0.8 \\
\hline Finland & $20 / 1,073$ & 1.9 & $50 / 1,541$ & 3.2 \\
\hline France & $119 / 1,073$ & 11.1 & $209 / 1,541$ & 13.6 \\
\hline Hungary & $8 / 1,073$ & 0.7 & $19 / 1,541$ & 1.2 \\
\hline Italy & $73 / 1,073$ & 6.8 & $136 / 1,541$ & 8.8 \\
\hline Lithuania & $67 / 1,073$ & 6.2 & $58 / 1,541$ & 3.8 \\
\hline Navarre, Spain & $242 / 1,073$ & 22.6 & $290 / 1,541$ & 18.8 \\
\hline The Netherlands & $40 / 1,073$ & 3.7 & $63 / 1,541$ & 4.1 \\
\hline Portugal & 49/1,073 & 4.6 & $29 / 1,541$ & 1.9 \\
\hline Romania & $90 / 1,073$ & 8.4 & $103 / 1,541$ & 6.7 \\
\hline Spainc & $334 / 1,073$ & 31.1 & $571 / 1,541$ & 37.1 \\
\hline
\end{tabular}

I MOVE+: Integrated Monitoring of Vaccines in Europe plus.

${ }^{a} \mathrm{~N}$ represents the total number of cases or controls with available information.

${ }^{\mathrm{b}}$ Defined as body mass index $\geq 30 \mathrm{~kg} / \mathrm{m}^{2}$.

${ }^{\mathrm{c}}$ Excluding Navarre. 
TABLE 2

Seasonal influenza vaccine effectiveness against influenza influenza A(H3N2) overall and stratified by patient characteristics, I-MOVE + study, Europe, influenza season 2016/17

\begin{tabular}{|c|c|c|c|c|c|c|}
\hline Population and patient characteristics & Vaccinated /cases & $\%$ & Vaccinated /controls & $\%$ & Adjusted IVE & $95 \% \mathrm{Cl}$ \\
\hline Aged 65 years and above - age/time ${ }^{\mathrm{a}}$ & $556 / 1,073$ & 52 & $894 / 1,541$ & 58 & 17 & 1 to 31 \\
\hline Aged 65 years and above - full model ${ }^{a}$ & $544 / 1,041$ & 52 & $868 / 1,494$ & 58 & 14 & -3 to 29 \\
\hline Aged 65-79 years - age/time ${ }^{a}$ & $175 / 457$ & 38 & $382 / 770$ & 50 & 25 & 2 to 43 \\
\hline Aged 80 years and above - age/time & $381 / 616$ & 62 & $512 / 771$ & 66 & 13 & -12 to 32 \\
\hline \multicolumn{7}{|l|}{ According to underlying diseases } \\
\hline Diabetes mellitus & $183 / 320$ & 57 & $295 / 468$ & 63 & 22 & -8 to 44 \\
\hline Heart disease & $378 / 703$ & 54 & $622 / 1,024$ & 61 & 19 & -1 to 35 \\
\hline Lung disease & $209 / 386$ & 54 & $440 / 668$ & 66 & 35 & 14 to 51 \\
\hline Cancer & $105 / 198$ & 53 & $227 / 362$ & 63 & 21 & -19 to 47 \\
\hline At least two underlying chronic diseases & $414 / 767$ & 54 & $732 / 1,196$ & 61 & 17 & -2 to 33 \\
\hline \multicolumn{7}{|l|}{ According to previous vaccination } \\
\hline Not vaccinated in $2015 / 16$ & $46 / 473$ & 10 & $99 / 623$ & 16 & 39 & -3 to 59 \\
\hline Vaccinated in $2015 / 16$ & $502 / 572$ & 88 & $776 / 887$ & 87 & -2 & -44 to 28 \\
\hline \multicolumn{7}{|l|}{ Sensitivity analyses } \\
\hline Swabbed within 3 days & $502 / 872$ & 58 & $333 / 629$ & 53 & 8 & -16 to 28 \\
\hline No antivirals before swabbing & $867 / 1,446$ & 60 & $509 / 904$ & 56 & 14 & -3 to 29 \\
\hline
\end{tabular}

I MOVE+: Integrated Monitoring of Vaccines in Europe plus.

a Variables used for adjustment:

-age/time: adjusted for study site, age and onset date (modelled as a restricted cubic spline with 3 and 4 knots respectively);

-full model: adjusted for study site, onset date, age (modelled as a restricted cubic spline with 3 and 4 knots respectively), lung diseases, heart diseases, diabetes, obesity, renal diseases, cancer and hospitalisation in the past 12 months;

-other estimates were adjusted for study site, onset date, age (modelled as a restricted cubic spline with 3 and 4 knots respectively) and hospitalisation in the past 12 months.

hospitalised with signs compatible with a severe acute respiratory infection (SARI) defined as at least one systemic and one respiratory sign or symptom. Swabs were tested with reverse-transcriptase polymerase chain reaction (RT-PCR) for influenza $A\left(\mathrm{H}_{3} \mathrm{~N}_{2}\right), A\left(\mathrm{H}_{1} \mathrm{~N}_{1}\right)$ pdmog and $B$. We compared the odds of vaccination between patients positive for influenza $A\left(\mathrm{H}_{3} \mathrm{~N}_{2}\right)$ virus and those negative for any influenza virus. We calculated IVE as (1-odds ratio (OR)).

We measured IVE stratified by age group (65-79 yearolds and $\geq 80$ year-olds), presence of underlying conditions (diabetes mellitus, cancer, heart or lung disease, and presence of at least two underlying chronic diseases) and 2015/16 seasonal influenza vaccination status. In a one-stage approach, using logistic regression with the study site as a fixed effect, we adjusted IVE estimates for date of symptoms onset, age (as cubic splines) and individual underlying conditions. Using patients unvaccinated in both 2015/16 and 2016/17 seasons as a reference, we computed the effectiveness of being vaccinated in 2015/16 season only, in 2016/17 season only and in both seasons.

\section{Vaccine effectiveness against influenza $\mathrm{A}(\mathrm{H} 3 \mathrm{~N} 2)$ in $2016 / 17$}

We included 1,073 influenza $A\left(\mathrm{H}_{3} \mathrm{~N}_{2}\right)$ cases, nine $\mathrm{A}\left(\mathrm{H}_{1} \mathrm{~N}_{1}\right)$ pdmog cases, 13 cases of influenza $B$ and 1,541 controls between week 47, 2016 and week 14, 2017.
Due to the small number of cases, we were not able to measure IVE against influenza $A\left(\mathrm{H}_{1} \mathrm{~N}_{1}\right)$ pdmog and $B$. We excluded these 22 records from all analyses.

The median age of $\mathrm{A}\left(\mathrm{H}_{3} \mathrm{~N}_{2}\right)$ cases was 81 years (range: 65-102 years) while that of controls was 80 (range: 65-102 years). Ninety-four percent of cases and 95\% of controls had at least one underlying condition $(p=0.14)$. Controls were more likely than cases to have underlying lung disease (44 vs 37\%, p<0.05), rheumatologic disease (22 vs 15\%, p<0.05) and cancer (24 vs $19 \%, p<0.05)$, to have been hospitalised in the past 12 months ( 44 vs 33\%, p<0.05) and to be current smokers (26 vs 20\%, p<0.05) (Table 1).

The one-stage pooled adjusted IVE was $17 \%$ (95\% confidence interval $(\mathrm{Cl}): 1$ to 31$)$ overall; $25 \%(95 \% \mathrm{Cl}: 2$ to 43 ) among patients aged 65-79 years and 10\% (95 $\% \mathrm{Cl}:-15$ to 30 ) among those aged 80 years and above. Among patients with specific underlying conditions, IVE ranged between $19 \%$ ( $95 \% \mathrm{Cl}:-1$ to 35$)$ among patients with heart disease and $35 \%$ (95\% Cl: 14 to 51 ) among patients with lung disease (Table 2).

The $2016 / 17$ seasonal IVE was $-2 \%$ ( $95 \% \mathrm{Cl}:-44$ to 28 ) among patients who had received 2015/16 seasonal influenza vaccine and $39 \%(95 \% \mathrm{Cl}:-3$ to 59$)$ among patients not vaccinated in 2015/16 (Table 2). Taking as a reference patients unvaccinated in 2015/16 and 
TABLE 3

Seasonal influenza vaccine effectiveness against influenza A(H3N2) by vaccine uptake in 2015/16, 2016/17 and in both seasons, I-MOVE + study, Europe, influenza season 2016/17

\begin{tabular}{|l|c|c|c|c|}
\hline $\begin{array}{l}\text { Vaccine uptake in 2015/16 } \\
\text { and 2016/17 influenza } \\
\text { seasons }\end{array}$ & Cases & Controls & IVE & $95 \% \mathrm{Cl}$ \\
\hline Not vaccinated & 427 & 524 & \multicolumn{2}{|c|}{ Reference } \\
\hline $2016 / 17$ only & 46 & 99 & 38 & 9 to 58 \\
\hline $2015 / 16$ only & 70 & 111 & 19 & -15 to 42 \\
\hline Vaccinated in both seasons & 502 & 776 & 15 & -3 to 30 \\
\hline
\end{tabular}

$\mathrm{Cl}$ : confidence interval; I-MOVE+: Integrated Monitoring of Vaccines in Europe plus; IVE: influenza vaccine effectiveness.

a Adjusted for study site, age and onset date (modelled as a restricted cubic spline with 3 and 4 knots, respectively).

The $\mathrm{A}\left(\mathrm{H}_{3} \mathrm{~N}_{2}\right)$ vaccine components were $\mathrm{A} / \mathrm{Sw}$ itzerland/2013 (3C.3a) in the $2015 / 16$ seasonal vaccine and A/Hong Kong/2014 (3C.2a) in the $2016 / 17$ seasonal vaccine.

$2016 / 17$, IVE for those vaccinated in $2015 / 16$ only was $19 \%(95 \% \mathrm{Cl}:-15$ to 42$)$ and IVE when vaccinated both in $2015 / 16$ and $2016 / 17$ was $15 \%(95 \% \mathrm{Cl}:-3$ to 30$)$ (Table 3).

\section{Discussion}

In the 2016/17 influenza season, $\mathrm{A}\left(\mathrm{H}_{3} \mathrm{~N}_{2}\right)$ viruses largely predominated. IVE against hospitalisation with influenza $A\left(\mathrm{H}_{3} \mathrm{~N}_{2}\right)$ virus infection among persons aged 65 years and above was low at $17 \%$. The IVE point estimate was even lower (10\%) among patients aged 80 years and above. IVE was similar among patients with heart disease, diabetes mellitus and cancer. The IVE point estimate was higher among patients with lung disease. While 95\% Cls were largely overlapping, the $2016 / 17$ IVE point estimate was lower (IVE: -2\%) among patients vaccinated also in 2015/16 than among those unvaccinated in 2015/16 (IVE: 39\%).

Low IVE against influenza $\mathrm{A}\left(\mathrm{H}_{3} \mathrm{~N}_{2}\right)$ among persons aged 65 years and above has been previously observed in hospital settings [6-8]. A recent meta-analysis measured that the pooled IVE against hospitalisation with influenza $\mathrm{A}\left(\mathrm{H}_{3} \mathrm{~N}_{2}\right)$ in seasons when circulating and vaccine strains were antigenically different was $14 \%$ (95\% Cl: -3 to 30 ) among persons aged 65 years and above [9]. It was $43 \%(95 \% \mathrm{Cl}: 33$ to 53$)$ in seasons when circulating and vaccine $\mathrm{A}\left(\mathrm{H}_{3} \mathrm{~N}_{2}\right)$ strains were antigenically similar; $48 \%(95 \% \mathrm{Cl}: 37$ to 59$)$ against influenza $A\left(\mathrm{H}_{1} \mathrm{~N}_{1}\right)$ pdmog and $38 \%(95 \% \mathrm{Cl}: 25$ to 53$)$ against influenza B [9].

Based on specimens received from week 40/2016 to week 5/2017, available antigenic data from the World Health Organization (WHO) European Region indicated that most circulating viruses that could be analysed were considered as antigenically similar to the 2016/17 vaccine component [10]. Consequently, European data supported the WHO recommendation to maintain the same vaccine component A/Hong Kong/4801/2014 (clade $3 \mathrm{C} .2 \mathrm{a})$ for influenza $\mathrm{A}\left(\mathrm{H}_{3} \mathrm{~N}_{2}\right)$ in the $2017 / 18$ season vaccine for the northern hemisphere [11]. However, one third of viruses isolated during the above-mentioned period could not be assigned to an antigenic reporting category, reflecting technical challenges or antigenic changes in circulating viruses. Genetic data from Europe centralised at the ECDC suggested that circulating $A\left(\mathrm{H}_{3} \mathrm{~N}_{2}\right)$ viruses had undergone considerable genetic diversification during the above-mentioned period, with the emergence of subclusters within clade 3 C.2a and subclade 3C.2a1 [10].

In September 2017, WHO updated the $\mathrm{A}\left(\mathrm{H}_{3} \mathrm{~N}_{2}\right)$ component to A/Singapore/INFIMH-16-0019/2016 (subclade 3 C.2a1) in the 2018 seasonal vaccine for the southern hemisphere [12]. The latest WHO update on 2 October 2017, reported that influenza $A\left(H_{3} N_{2}\right)$ viruses were still predominating worldwide in September 2017. Further genetic information was not provided at this stage [13]. Our results taking patients unvaccinated in both 2015/16 and 2016/17 seasons as a reference suggested that influenza vaccination in 2015/16 and/or 2016/17 reduced the risk of influenza-associated hospitalisation among vaccinated patients. Our stratified results suggested that 2015/16 vaccination modified the $2016 / 17$ IVE. Although too imprecise to be conclusive, our results could suggest that patients vaccinated in both seasons benefited from a residual protection from the $2015 / 16$ vaccine, with no additional effect of the $2016 / 17$ vaccine uptake.

\section{Conclusion}

Our results suggest a low IVE against hospitalised influenza $A\left(\mathrm{H}_{3} \mathrm{~N}_{2}\right)$ among persons aged 65 years and above, particularly among patients aged 80 years and above. They also suggest a modifying effect of 2015/16 influenza vaccination on 2016/17 IVE. The $\mathrm{A}\left(\mathrm{H}_{3} \mathrm{~N}_{2}\right)$ virus component included in the $2017 / 18$ vaccine will remain the same as in the $2016 / 17$ season. The latest WHO influenza surveillance report suggests that influenza $\mathrm{A}\left(\mathrm{H}_{3} \mathrm{~N}_{2}\right)$ viruses were predominating worldwide in August 2017. Low IVE may be expected during the $2017 / 18$ season in case of predominant circulation of $A\left(\mathrm{H}_{3} \mathrm{~N}_{2}\right)$ viruses. However, IVE against influenza $A\left(H_{1} N_{1}\right) p d m o g$ and $B$ are usually reported to be higher. Close monitoring of virological surveillance data will be required to prompt early promotion of complementary measures such as the use of antivirals or non-pharmaceutical interventions.

Members of the I-Move + hospital working group

EpiConcept: Marta Valenciano

Spain: F. Pozo (National Centre for Microbiology, National Influenza Reference Laboratory, WHO-National Influenza Centre, Institute of Health Carlos III), M. García, M. Latorre (Dirección General de Salud Pública, Aragón), M. Omeñaca (H.U. Miguel Servet, Aragón), M. Oribe Amores, N. Muñoz (Subdirección de Salud Pública Gipuzkoa, País Vasco), G. Cilla (H. U. Donostia, Pais Vasco) 
Navarre: L Fernandino, I Martínez-Baz (Instituto de Salud Pública de Navarra, Pamplona), A Navascués, A Pérez-García, A Aguinaga, C Ezpeleta (Complejo Hospitalario de Navarra, IdiSNA, Pamplona, Spain)

Italy: A. Bella, Eva Charlotte Appelgren, M.R. Castrucci, S. Puzelli (Istituto Superiore di Sanità, Rome), M.Chironna, C. Germinario (Policlicnico Hospital, University of Bari); F. Ansaldi, I. Manini, E. Montomoli (Department of Molecular and Developmental Medicine, University of Siena)

Romania: E. Lupulescu, M. Lazar, M.E. Mihai, C.M Cherciu, S. Dinu, C. Tecu (National Institute for Research Cantacuzino), M. Nitescu, R. Bacruban, D. Azamfire, A. Dumitrescu, E. lanosik. (INBI Prof Dr Matei Bals, Bucuresti), E. Ceausu, C. P. Popescu, SA. Florescu, G. Târdei (Spitalul Clinic de Boli Infectioase si Tropicale Victor Babes, Bucuresti), C. Bejan, A. Teodor, G. Juganariu, C. Plesca, E. Duca (Spitalul Clinic de Boli Infectioase Sf. Parascheva, Iasi)

France: N. Lenzi, Z. Lesieur [Inserm, F-CRIN, Innovative clinical research network in vaccinology (I-REIVAC)], P. Loulergue (CIC De Vaccinologie, Cochin-Pasteur Paris, I-REIVAC), F. Galtier (Hôpital Saint-Eloi, CHU de Montpellier, I-REIVAC), C. Agostini, M. Ray, C. Merle, V. Foulongne (CHU de Montpellier), B. Lina (Université Lyon 1, CNR Virus Influenza France Sud, Lyon), F. Lainé (Hôpital Pontchaillou, CHU de Rennes, I-REIVAC), S. De Guibert, G. Lagathu, P. Tattevin, S. Jouneau, A. Esvant, T. le Gallou (Hôpital Pontchaillou, CHU de Rennes), F. Carrat (UPMC Univ Paris 06, IPLESP UMRS 1136, Public health department, Hôpital Saint-Antoine, Paris), G. Mawuvi, F. CHAU (UMRS 1136, Paris).

Finland: H. Nohynek, A. Haveri (National Institute for Health and Welfare)

Lithuania: G. Gefenaite, D. Velyvyte (Department of Infectious Diseases of Lithuanian University of Health Sciences, Kaunas, Lithuania) L. Jancoriene, B. Zablockiene, A. Ambrozaitis (Clinic of Infectious, Chest Diseases, Dermatovenerology and Allergology, Vilnius University Faculty of Medicine, Vilnius, Lithuania; Centre of Infectious Diseases, Vilnius University Hospital Santaros Klinikos, Vilnius, Lithuania), R. Grimalauskaite, G. Damuleviciene, V. Lesauskaite (Department of Geriatrics, Lithuanian University of Health Sciences, Kaunas, Lithuania), A. Bagdonas (Department of Internal Medicine, Lithuanian University of Health Sciences)

Portugal: B. Nunes, I. Kislaya, A.P. Rodrigues (National Health Institute Doutor Ricardo Jorge, Lisbon), V. Gomes, R. Côrte-Real (Centro Hospitalar de Lisboa Central, Lisbon), J. Poças, M.J. Peres (Centro Hospitalar de Setúbal, Setúbal)

Croatia: Bernard K., S. Kurecic-Filipovic, V. Visekruna Vucina (Croatian Institute of Public Health), A. Topic, N. Papic, J. Budimir (University Hospital for Infectious Diseases "Dr.Fran Mihaljevic")

Hungary: B. Oroszi (Office of the Chief Medical Officer, Budapest)

The Netherlands: A. Meijer, W. van der Hoek (National Institute for Public Health and the Environment (RIVM), Bilthoven), P.M. Schneeberger (Jeroen Bosch Hospital, 's Hertogenbosch)

\section{Acknowledgements}

Funding: The I-MOVE+ project has received funding from the European Union's Horizon 2020 research and innovation programme under grant agreement No 634446. The Lithuanian I-MOVE+ study sites were supported by a grant from the
Research Council of Lithuania (SEN-03/2015). We are grateful to all patients, medical staff, study nurses and epidemiologists from the 12 study sites who actively participated in the study.

Poland: Iwona Paradowska-Stankiewicz, Monika Korczyńska, Lidia Brydak, Katarzyna Cieślak, Dorota Kowalczyk, Karol Szymański, NIPH, NIH Poland. All participating GPs, Epidemiologists and Virologists from SES in Poland

Finland: Jukka Jokinen, Outi Lyytikäinen and Arto Palmu (study design, protocol writing), Päivi Sirén (clinical data collection), Esa Ruokokoski (data management), The laboratory staff in Viral Infections Unit of THL, Tampere University Hospital, Hatanpää Hospital (collaboration with the clinical work and data collection).

France: Hôpital Cochin, Paris: J. Charpentier, N. Marin, B. Doumenc, C. Le jeunne, A. Krivine, D. Dusser, S. Momcilovic, F. Terrier. CHU de Rennes: N. Belhomme, S. Simon, S. Cochennec, A. Reilhac, F. Erhel, C. Doudnikoff, J. Fouchard, B. Lefeuvre. Hôpital Edouard Herriot, Lyon: T. Benet, S. Amour, L. Henaff. Hôpital Saint-Eloi, Montpellier: P. Géraud, M. Berthelot, V. Driss, A. le Quellec, A. Bourdin, L. Landreau, A. Konaté, P. Corne, M. Sebbane, K. Klouche, M.S. Léglise, H. Goin.

\section{Conflict of interest}

None declared.

\section{Authors' contributions}

Marc Rondy was involved in the original methodological design of the study (generic protocol). He coordinated the European hospital IVE network, undertook the statistical analysis on which the research article is based and led the writing of the research article.

Alain Moren initiated the original methodological design of the study. He coordinated the European hospital IVE network and contributed to the writing of the research article.

Alin Gherasim, Itziar Casado, Odile Launay, Caterina Rizzo, Daniela Pitigoi, Aukse Mickiene, Sierk D. Marbus, Ausenda Machado, Ritva S. Syrjänen, Iva Pem-Novosel, Judith Krisztina Horváth, Amparo Larrauri, Jesús Castilla, Philippe Vanhems, Valeria Alfonsi, Alina E. Ivanciuc, Monika Kuliese, $A B$ van Gageldonk-Lafeber, Veronica Gomez, Niina Ikonen, Zvjezdana Lovric and Annamária Ferenczi were responsible for the coordination of the study at the local level. They were in charge of the data collection and management. They read, contributed to and approved the final version of the manuscript.

The I-MOVE+ hospital working group contributors contributed to developing the study site specific protocol. They were in charge of supervising the study at the hospital level and collect the data published in this research article. They read, contributed to and approved the final version of the manuscript.

\section{References}

1. European Centre for Disease Prevention and Control (ECDC) / World Health Organization Regional Office for Europe (WHO/ Europe). Joint ECDC-WHO/Europe weekly influenza update - Week 20/2017 (15 - 21 May 2017). ECDC-WHO/Europe. [Accessed 20 Jun 2017]. Available from: https://flunewseurope. org/Archives 
2. European Centre for Disease Prevention and Control (ECDC). Risk assessment of seasonal influenza, EU/EEA, 2016-2017 - Update. Stockholm: ECDC; 25 Jan 2017. Available from: http://ecdc.europa.eu/en/publications/Publications/Riskassessment-seasonal-influenza-2016-2017-update.pdf

3. Kissling E, Rondy MI-MOVE/I-MOVE+ study team. Early 2016/17 vaccine effectiveness estimates against influenza $A\left(\mathrm{H}_{3} \mathrm{~N}_{2}\right)$ : I-MOVE multicentre case control studies at primary care and hospital levels in Europe. Euro Surveill. 2017;22(7):30464. https://doi.org/10.2807/1560-7917.ES.2017.22.7.30464 PMID: 28230524

4. Integrated Monitoring of Vaccines in Europe plus (I-MOVE+). [Internet]. [Accessed 10 October 2017]. Available from: http:// www.i-moveplus.eu/wp2

5. Rondy M, Larrauri A, Casado I, Alfonsi V, Pitigoi D, Launay $O$, et al. 2015/16 seasonal vaccine effectiveness against hospitalisation with influenza $A\left(\mathrm{H}_{1} \mathrm{~N}_{1}\right)$ pdmog and $B$ among elderly people in Europe: results from the I-MOVE+ project. Euro Surveill. 2017;22(30):30580. https://doi. org/10.2807/1560-7917.ES.2017.22.30.30580 PMID: 28797322

6. McNeil SA, Andrew MK, Ye L, Haguinet F, Hatchette TF, ElSherif $M$, et al. Interim estimates of 2014/15 influenza vaccine effectiveness in preventing laboratory-confirmed influenza-related hospitalisation from the Serious Outcomes Surveillance Network of the Canadian Immunization Research Network, January 2015. Euro Surveill. 2015;20(5):21024. https://doi.org/10.2807/1560-7917.ES2015.20.5.21024 PMID: 25677052

7. Puig-Barbera J, Mira-Iglesias A, Tortajada-Girbes M, LopezLabrador FX, Belenguer-Varea A, Carballido-Fernandez M, et al. Effectiveness of influenza vaccination programme in preventing hospital admissions, Valencia, 2014/15 early results. Euro Surveill. 2015;20(8):21044. https://doi. org/10.2807/1560-7917.ES2015.20.8.21044 PMID: 25742432

8. Rondy M, Puig-Barbera J, Launay O, Duval X, Castilla J, Guevara $M$, et al. 2011-12 seasonal influenza vaccines effectiveness against confirmed $\mathrm{A}\left(\mathrm{H}_{3} \mathrm{~N}_{2}\right)$ influenza hospitalisation: pooled analysis from a European network of hospitals. A pilot study. PLoS One. 2013;8(4):e59681. https://doi.org/10.1371/journal. pone.0059681 PMID: 23565159

9. Rondy M, El Omeiri N, Thompson MG, Levêque A, Moren A, Sullivan SG. Effectiveness of influenza vaccines in preventing severe influenza illness among adults: A systematic review and meta-analysis of test-negative design case-control studies. J Infect. 2017; $\bullet \bullet: S 0163-4453(17) 30299-2$.; Epub ahead of print. https://doi.org/10.1016/j.jinf.2017.09.010 PMID: 28935236

10. Melidou A, Broberg EEuropean region influenza surveillance network. Predominance of influenza $A\left(\mathrm{H}_{3} \mathrm{~N}_{2}\right)$ virus genetic subclade 3C.2a1 during an early 2016/17 influenza season in Europe - Contribution of surveillance data from World Health Organization (WHO) European Region to the WHO vaccine composition consultation for northern hemisphere $2017 / 18$. Vaccine. 2017;35(37):4828-35. https://doi.org/10.1016/j. vaccine.2017.07.057 PMID: 28780977

11. World Health Organization (WHO). Recommended composition of influenza virus vaccines for use in the 2017-2018 northern hemisphere influenza season. Geneva: WHO; 1 Mar 2017. Available from: http://www.who.int/influenza/vaccines/virus/ recommendations/2017_18_north/en/

12. World Health Organization (WHO). Recommended composition of influenza virus vaccines for use in the 2018 southern hemisphere influenza season. Geneva: WHO; 28 Sep 2017. Available from: http://www.who.int/influenza/vaccines/virus/ recommendations/2018_south/en/

13. World Health Organization (WHO). Influenza Update $\mathrm{N}^{\circ} 299$. Geneva: WHO; 2 Oct 2017. Available from: http://www. who.int/influenza/surveillance_monitoring/updates/ latest update GIP surveillance/en

\section{License and copyright}

This is an open-access article distributed under the terms of the Creative Commons Attribution (CC BY 4.0) Licence. You may share and adapt the material, but must give appropriate credit to the source, provide a link to the licence, and indicate if changes were made.

This article is copyright of the authors, 2017. 